\title{
LICENÇA-PATERNIDADE À BRASILEIRA: UMA ANÁLISE CRÍTICA DO MARCO LEGAL DA PRIMEIRA INFÂNCIA
}

\author{
Samuel Spellmann ${ }^{298}$
}

\begin{abstract}
RESUMO
O presente artigo busca demonstrar a importância da licença-paternidade para a valorização do trabalho feminino e para a mudança de entendimento acerca da paternidade, melhorando as relações entre pais e filhos. Iniciamos nossa argumentação através da exposição da legislação existente no Brasil, tecendo comentários sobre a Lei ${ }^{\circ} 11.770 / 08$, que institui o Programa da Empresa Cidadã. Após, buscamos demonstrar, partindo de diversos estudos, as íntimas conexões entre o direito à licença-paternidade e a valorização do trabalho feminino. Por fim, analisamos o texto da Lei $n^{\circ} 13.257 / 16$, que institui o Marco Legal da Primeira Infância. Concluímos pela necessidade de um regime legal de licença-paternidade que seja independente e dissociada entre os pais.
\end{abstract}

Palavras-chave: Licença-paternidade. Direito Social. Trabalho Feminino.

\section{INTRODUÇÃO}

O presente artigo busca demonstrar, a partir de pesquisa bibliográfica derivada de análises da legislação nacional e da experiência estrangeira, a importância de uma maior extensão e difusão do direito social à licença-paternidade para a República Federativa do Brasil.

Observamos, para tanto, a mudança no trato da divisão sexual do trabalho ao longo da segunda metade do século XX, fazendo remissões às origens do direito de se ausentar do local de trabalho sem perda de remuneração para o cuidado daqueles que acabam de surgir.

Analisamos a situação internacional, na qual, como nos demais direitos sociais, lutas e resistências desembocaram em mudanças legais, observando então seus reflexos nas ideias e movimentos políticos no Brasil, os quais desembocaram na nossa própria versão dos direitos também alcançados no exterior.

Explicamos os pormenores da licença-maternidade no Brasil, bem como apresentamos outros direitos ligados à proteção da família, comparando estes com a legislação existente acerca do direito à licença-paternidade.

\footnotetext{
${ }^{298}$ Advogado. Graduado em Direito pela Universidade Estadual da Paraíba - UEPB. Aluno Especial do Programa de Pós-Graduação do Mestrado de Serviço Social da UEPB. Endereço eletrônico: samuelspellmann @ hotmail.com.
} 
Em tópico subsequente encontra-se a nossa análise da conexão intrínseca que se estabelece entre o direito à licença-paternidade e a proteção e valorização do trabalho feminino.

Após, se dá a exposição crítica acerca da experiência social e legal do direito à licençapaternidade no exterior, cujo protagonismo se deu nas socialdemocracias escandinavas, e que, embora carreguem semelhanças legais para além desta particular seara, apresentam particularidades inquietantes quanto à implementação do direito social à licença paternidade. Apresentamos também o caso espanhol, o qual parece indicar um possível caminho a se seguir para a implementação gradual do direito à licença-paternidade.

Seguem, por fim, as considerações finais referentes ao presente artigo.

Embora sejamos críticos a forma pela qual se alcançou e se difundiu o direito à licençapaternidade instituído pela Lei $n^{\circ}$ 13.257/16 - através de mudança na Lei da Empresa Cidadã, bem como na CLT -, compreendemos que ocorrerão melhorias efetivas na condição laboral para ambos os gêneros. É louvável a aprovação de qualquer melhoria em matéria de direitos, como ocorreu no último dia Internacional da Mulher.

Por fim, esperamos que, uma vez alcançado por poucos, o direito à licença-paternidade tome força suficiente para que venha abarcar todos os trabalhadores do país. É nesse espírito, em meio a avanços e retrocessos históricos e legais, que se desenvolveu este texto.

\section{A CONSTRUÇÃo HISTÓRICA E DISCIPLINAÇÃO LEGAL DOS DIREITOS À LICENÇA-MATERNIDADE E À LICENÇA-PATERNIDADE}

\subsection{Considerações Iniciais}

A participação no mundo do trabalho não-doméstico pelas mulheres está associada à necessidade de aumentar a renda familiar e ao gradual aumento no nível de escolaridade, fatores que reverberam seus efeitos nas alterações da taxa de natalidade (GALIZA; FONTOURA; PINHEIRO, 2009).

A mulher passa, a partir de determinado momento histórico, a ocupar duas esferas contrapostas de trabalho: uma voltada ao ambiente doméstico ${ }^{299}$, com seu cerne no cuidado dos filhos e manutenção da residência; e outra voltada à busca por este aumento de renda familiar.

\footnotetext{
${ }^{299}$ Que permanece sendo esfera de trabalho dominantemente feminina pela não socialização de seus custos, estes sendo denotados, como afirmam Abramo e Todaro (2008), como "bens gratuitos fornecidos pela natureza" - desconsideráveis da margem de cálculo, portanto vistos como se não custassem esforço nenhum advindo de ninguém.
} 
Neste viés, asseveram Abramo e Todaro (2005, p. 20),

\begin{abstract}
A preocupação com o trabalho das mulheres entra tardiamente na disciplina econômica. Os economistas clássicos estavam emaranhados numa contradição, ao reconhecer o trabalho das mulheres na família, mas sem incorporá-lo em um esquema analítico que representasse o sistema socioeconômico global. A economia neoclássica nem sequer coloca como problema a conceituação das atividades das mulheres na família como trabalho social.
\end{abstract}

Confrontadas com a realidade de múltiplas jornadas laborais, mulheres, agora incorporadas ao mercado de trabalho, empreenderam lutas, campanhas e mobilizações para que ocorressem mudanças na compreensão e no significado de seu trabalho. (ABRAMO; TODARO, 2005)

Assim, alcançaram-se certos direitos trabalhistas, dentre os quais à licença-maternidade. Tais benefícios, entendidos como custos não-salariais (como as contribuições do empregador à previdência social, àqueles relacionados a demissões e contratações, acidentes de trabalho e enfermidades) deram origem à discussão acerca de como os custos de trabalho se relacionam com o nível de emprego numa sociedade. (ABRAMO; TODARO, 2005)

Todavia, é também necessário que se perceba que, embora seja marcante para uma época a possibilidade da passagem da mulher do ambiente de trabalho doméstico para a esfera do trabalho remunerado, marcado agora pela legislação protetiva, não se pode deixar de lado o fato de que, como asseveram Galiza, Fontoura e Pinheiro (2009, p. 852-853),“[...] Para as mulheres de classes mais baixas, por exemplo, a entrada no mercado de trabalho - como resposta a uma necessidade de complementar a renda familiar - já era uma realidade há muito mais tempo.”.

É nesse viés que ressaltamos, dando início a nossa argumentação, que, mesmo havendo alterações legais que beneficiem, como beneficiaram as mulheres em sua luta por direitos, estas se restringem às trabalhadoras subordinadas, privadas e públicas, abarcadas pela CLT e demais legislações de cunho laboral (GALIZA; FONTOURA; PINHEIRO, 2009). Há, portanto, todo um universo de pessoas não protegidas pela legislação trabalhista em vigor, que inclusive constituiu no Brasil a maior parte dos trabalhadores até bem recentemente, e que constitui um seguimento que tem apresentado crescimento (EXAME, 2016).

Segue-se breve explanação sobre o reconhecimento das primeiras bases legais internacionais dos direitos relativos à maternidade, bem como dos direitos alcançados no Brasil.

2.2 A Licença-maternidade no ordenamento jurídico brasileiro.

Está elencado expressamente enquanto direito social a proteção à maternidade e à infância, através do caput do art. $6^{\circ}$ da Constituição Federal. 
Na Carta Magna se estabelece também que a família, como base da sociedade, tem especial proteção do Estado e que os direitos e deveres que fazem referência à sociedade conjugal são exercidos igualmente pelo homem e pela mulher (art. $226, \S 5^{\circ}$, da CF).

A seguir, a Constituição deixa claro que é dever compartilhado entre a família, a sociedade e o Estado, assegurar à criança e ao adolescente, com absoluta prioridade, o direito à vida, à saúde, à alimentação, à educação, ao lazer, à profissionalização, à cultura, à dignidade, ao respeito, à liberdade e à convivência familiar e comunitária, além de colocados à salvo de toda forma de negligência, discriminação, exploração, violência crueldade e opressão (art. 227, da CF). (THOMÉ, 2009)

Estes são os fundamentos constitucionais que, de caráter programático, estabelecem a intrínseca conexão entre a proteção da família e o cuidado dos filhos.

$\mathrm{O}$ direito à licença-maternidade é expressamente garantido na Constituição Federal. Além disso, sua duração é estabelecida pelo mesmo inciso, sendo esta a de cento e vinte dias (art. $7^{\circ}$, inciso XVIII, da CF).

Por fim, existe estrita relação entre a proteção à maternidade e o princípio constitucional da proteção do mercado de trabalho da mulher, disposto no inciso XX do art. $7^{\circ}$, da Constituição Federal. $\mathrm{Na}$ medida em que as trabalhadoras têm seu retorno ao trabalho e sua remuneração durante o afastamento garantidas, menos se prejudicam as crianças pelo retorno demasiado prematuro de suas mães ao trabalho, como também não se penalizam mulheres pela maternidade. (ABRAMO; TODARO, 2005)

A proteção à maternidade, contudo, nem sempre foi constante em nosso ordenamento jurídico, passando por diversas transformações ao longo do século passado. No Brasil, a primeira manifestação a respeito da proteção à maternidade se deu pelo Decreto Federal nº 16.300 de 21/12/1923, que previa o descanso de 30 dias antes e após o parto. (SILVA, 2007)

A assistência médica e sanitária à gestante foi garantida pela Constituição Brasileira de 1934, de viés socialdemocrata. Contudo, com o golpe do Estado Novo, a Constituição outorgada de Getúlio Vargas não possuía em seu texto a garantia de emprego à gestante. (NEIVERTH; MANDALOZZO, 2009).

Em antítese à restrição de direitos trazida pela Carta de 1937, foi em sua vigência que, por necessidade de unificação da espraiada legislação trabalhista que se promulgou a Consolidação das Leis Trabalhistas (CLT) em 1943, possuindo normas de proteção ao trabalho da mulher e garantindo a estabilidade no emprego e a licença-maternidade. (NEIVERTH; MANDALOZZO, 2009).

Originalmente instituída pela proibição de trabalhar que vigorava a partir de seis semanas antes até seis semanas após o nascimento, a licença-maternidade sofreu alteração de seu texto no art. 
392, da CLT em ocasião do Decreto lei no 229 de 1967, que alterou o período da licença para quatro semanas antes e oito após, fazendo permanecer o tom proibitivo do texto legal.

Embora ocorrendo mudanças em 1967 no Capítulo III, da CLT que tratava da proteção do trabalho da mulher através do Decreto supracitado, as Constituições de 1946 e 1967 não inovaram na proteção à maternidade. (NEIVERTH; MANDALOZZO, 2009).

Terminada a Ditadura Militar, com a promulgação da Constituição Federal de 1988, após diversos debates, assegurou-se a igualdade entre homens e mulheres, mantendo-se o tratamento dissonante apenas onde este é inegável, e no já citado art. $7^{\circ}$, XVIII, foi ampliada a licença maternidade para cento e vinte dias. (NEIVERTH; MANDALOZZO, 2009).

Nas condições atuais, a CLT reserva capítulo específico referente à Proteção ao Trabalho da Mulher, do artigo 372 ao 401, estabelecendo que o afastamento da empregada poderá ter início entre o vigésimo oitavo dia anterior ao parto, regulado pelo $§ 1^{\circ}$, do art. 392 da Consolidação.

Além disto, tem a gestante direito à estabilidade desde a confirmação da gravidez até cinco meses após o parto, segundo preceito colocado no art. 10, II, "b", do Ato das Disposições Constitucionais Transitórias (ADCT).

Hoje, a licença-maternidade se estende às mães adotivas ou com guarda judicial para fins de adoção conforme disposto no art. 392-A da CLT, onde são dispostos: cento e vinte dias no caso de crianças de até um ano de idade; sessenta dias para crianças entre um e quatro anos de idade; e trinta dias no caso de crianças a partir de quatro anos até oito anos de idade.

Neiverth e Mandalozzo (2009, p. 5-6) elucidam em claros termos o pagamento da remuneração salarial às mães. Indicam que:

\begin{abstract}
No período de licença-maternidade é assegurado à mãe o valor de sua remuneração integral, segundo o artigo 72 da Lei 8.213/91. O pagamento do salário-maternidade, que em hipótese alguma deve ser ônus do empregador e sim da Previdência Social, no caso das empregadas domésticas é pago pela própria Previdência através da rede bancária; as demais empregadas seguradas recebem o pagamento pela empresa que deduz esse valor na Guia da Previdência Social, conforme a Lei 10.710 de 05/08/2003, exceto nos casos de adoção ou guarda judicial para fins de adoção, quando o pagamento é feito também pela Previdência Social através da rede bancária.
\end{abstract}

O salário-maternidade, vale salientar, é benefício de cunho previdenciário a que só tem direito as seguradas: empregada, empregada doméstica, a contribuinte individual e facultativa em ocasião do parto, de adoção ou de guarda judicial para fins de adoção. É direito estendido também a segurada especial - a produtora, a parceira, a meeira e a arrendatária rurais e a pescadora artesanal, que exerçam suas atividades em regime de economia familiar, nos conformes do art. 195, §8, da Constituição Federal - e à trabalhadora avulsa. (NEIVERTH; MANDALOZZO, 2009) 
A seguir se falará da ampliação em sessenta dias possibilitada pelo Programa Empresa Cidadã. ${ }^{300}$

\subsubsection{O Programa Empresa Cidadã}

O Programa Empresa Cidadã, instituído pela Lei n ${ }^{\circ}$ 11.770/08, busca ampliar o tempo de afastamento do local de trabalho da mulher empregada por sessenta dias além dos conferidos através do art. $7^{\circ}$, XVIII, da Constituição Federal.

Para tanto, o projeto elabora incentivo fiscal a ser concedido à empresa participante, esta concordando em prorrogar a licença-maternidade da trabalhadora e recebendo incentivo fiscal como contrapartida. O projeto, visto como incentivo ao aleitamento materno de seis meses, condição indispensável para a saúde da criança, entrou em vigor na sua data de publicação, mas só passou a surtir efeitos no exercício financeiro de 2010 (art. 8º da Lei $\mathrm{n}^{\mathrm{o}}$ 11.770/08). (NEIVERTH; MANDALOZZO, 2009)

É necessário, todavia, que a empresa que busca participar do Programa seja tributada com base no seu Lucro Real ${ }^{301}$ (art. $5^{\circ}$, da Lei $n^{\circ} 11.770 / 08$ ). Isto permitirá que lhe seja deduzido o imposto devido para cada período de apuração, nos conformes da LC 100/01, sendo este correspondente ao total da remuneração integral da empregada pagos nos sessenta dias de licença-maternidade estendida, vedada a dedução como despesa operacional.

Fica estabelecido que no período de prorrogação da licença-maternidade a empregada não poderá exercer qualquer atividade remunerada e a criança não poderá ser mantida em creche ou estabelecimento similar, ficando determinado que a finalidade legal é a de proporcionar um maior período de convivência na companhia da mãe, recebendo cuidados e amamentação. Descumprido tal condição, a empregada perderá o direito à prorrogação. (NEIVERTH; MANDALOZZO, 2009)

Evidente que a legislação corrente é, como afirmam Neiverth e Mandalozzo (2009, p.9-10), “enfocada sob o aspecto físico [...] [e] prevê que a mulher seja poupada de grandes esforços físicos,

\footnotetext{
300 É vital que se exponha que direito já é instituído na esfera do Executivo Federal através do Programa de Prorrogação da Licença à Gestante da Administração Pública Federal. O programa, instituído pelo Decreto 6.690/08, atinge toda a administração direta, e, na indireta, a autárquica e fundacional. Os demais entes da administração indireta - Empresas Públicas e Sociedades de Economia Mista -, por sua natureza ambivalente, voltada à exploração de atividades econômicas ou para a prestação de serviços públicos, são alcançados pela Lei n ${ }^{\circ} 11.770 / 08$. Além disso, a Resolução da Câmara dos Deputados $n^{\circ} 15 / 03$, que acrescentou o $\S 1^{\circ}$ ao art. 235 do Regimento Interno da Câmara dos Deputados, possibilitando a aplicação dos incisos XVIII e XIX do art. $7^{\circ}$, da Constituição Federal aos deputados e deputadas.

${ }^{301}$ Lucro real é a regra geral para a apuração do Imposto de Renda e da Contribuição Social sobre o Lucro Líquido da pessoa jurídica. Se trata da "base de cálculo do imposto sobre a renda apurada segundo registros contábeis e fiscais efetuados sistematicamente de acordo com as leis comerciais e fiscais" (RECEITA FEDERAL DO BRASIL). É aferido à partir do lucro contábil, apurado pela pessoa jurídica, acrescido de ajustes negativos e positivos requeridos pela legislação fiscal.
} 
trabalho em posições antifisiológicas, excessos microclimáticos, vibrações, fadiga física e barulho intenso."

Embora se possa conceber que em determinados postos de trabalho ocupados por mulheres nos quais se exerce atividade repetitiva e se pratica trabalho sem participação criativa - impossível não visualizar aqui o exemplo do setor industrial - o afastamento prolongado não surtirá maiores efeitos na dinâmica laboral da empresa, há de se convir que, em outros ramos, onde a subjetividade é essencial, a ausência será sentida. (NEIVERTH; MANDALOZZO, 2009)

Certas falhas na lei 11.770/08 são apontadas por diversos trabalhos. A intenção de aderir ao Programa Empresa Cidadã é vinculada à adesão ao tipo de tributação baseado no Lucro Real, impossibilitando a adesão por empresas cujas empregadas estejam interessadas no prolongamento temporal do direito conferido pelo art. $7^{\circ}$, XVIII, da Constituição Federal ${ }^{302}$. (NEIVERTH; MANDALOZZO, 2009)

Além disso, como só pode participar do programa a empregada vinculada a empresa que declare o lucro Real, o direito não é extensível à domésticas e rurais. (MILÍCIO, 2007)

Por fim, se deve atentar que, estabelecida a facultatividade na adesão ao programa, por óbvio se enfrentarão situações em que o desinteresse é expresso. E esta consequência indesejável só é possível pela escolha legislativa em disciplinar através de lei específica a progressão de um direito social ao invés de se alcançar alteração no quantum estabelecido no texto constitucional, extensível à todas as trabalhadoras. ${ }^{303}$ (CASTRO, 2008)

Inclusive, é através do Programa Empresa Cidadã e de modificação na Lei no 11.770/08 que se busca a extensão desse direito, ainda que limitado, aos pais das mesmas crianças. Isto será objeto de análise crítica adiante no presente trabalho.

\subsection{A Licença-paternidade no Brasil.}

Seguindo a disciplina constitucional da licença-maternidade, a licença-paternidade no é encontrada no art. $7^{\circ}$, XIX, da Constituição Federal. $\mathrm{O}$ artigo remete à esfera legal a disposição do quantum de licença-paternidade será oferecido aos trabalhadores do Brasil.

\footnotetext{
${ }^{302}$ Inclusive, ao se analisar os aspectos que diferenciam a escolha entre Lucro Real e Lucro Presumido, onde o volume de informações e detalhamentos é menor, se pode visualizar a facilidade e simplicidade na escolha deste último, muito utilizado por micro e pequenas empresas. Estas estarão afastadas do direito à licença-maternidade compreendido pelo Programa Empresa Cidadã, por mais boa vontade que tenham, no minuto em que escolherem seu regime tributário.

${ }^{303}$ Vários destes apontamentos coadunam com o apresentado por Fernanda Castro, em breve texto disponível em: < http://www.pstu.org.br/node/13737 >. Acesso em: 14 de fev. 2016.
} 
O Brasil optou, portanto, pelo sistema de licença dissociada entre os sexos, oposto ao sistema da licença-parental, não permitindo assim que um tempo compartilhado conferido por lei à ambos livremente disponível para o rearranjo, como certos sistemas legais adotados nos países nórdicos. Alguns casos nesse sentido serão analisados posteriormente neste trabalho.

Ainda sem lei promulgada, o art. $7^{\circ}$, XIX, da Constituição Federal tem sua eficácia restrita, subsistindo o direito à licença-paternidade na disposição do art. $10, \S 1^{\circ}$ do Ato das Disposições Constitucionais Transitórias - ADCT.

Como elucida Mendes (2014, p. 70), as normas constitucionais de eficácia limitada

[...] somente produzem os seus efeitos essenciais após um desenvolvimento normativo posterior, a cargo dos poderes constituídos. A sua vocação de ordenação depende, para ser satisfeita nos seus efeitos básicos, da interpolação do legislador infraconstitucional. São normas, pois, incompletas, apresentando baixa densidade normativa.

O ADCT é entendido como meio constitucional para salvaguardar certas disposições de interesse maior do constituinte com a proteção que usufruem as normas constitucionais, sem, contudo, elenca-las no próprio texto constitucional. Todavia não estarem no texto expresso da Carta, é soez no entendimento doutrinário o exposto por Mendes (2014, p.79): “As normas do ADCT são normas constitucionais e têm o mesmo status jurídico das demais normas do texto principal."

Para além da tutela constitucional, a disciplina acerca da licença paternidade é apresentada em diversos dispositivos legais, não abordados neste trabalho ${ }^{304}$.

\section{APONTAMENTOS ACERCA DO DIREITO À PROTEÇÃO DO TRABALHO DA MULHER E DA DESIGUALDADE SALARIAL ENTRE GENEROS}

Até aqui, o que se pode perceber é que, como ressaltam Fontoura, Galiza e Pinheiro (2009, p. 854), todavia os direitos ressaltados sejam voltados à proteção da família, tomando-se como ponto de partida a proteção à mulher em ocasião da maternidade, a focalização prioritária dos direitos reprodutivos femininos termina, embora indiretamente e de forma não intencional,

[...] por oferecer poucas possibilidades aos homens de se comprometerem com o exercício da paternidade responsável, bem como ignorando a existência de famílias homoafetivas e

\footnotetext{
304 A título de exemplo, o regime dos servidores da União, estabelecido pela Lei 8.112/90, prevê a licença-paternidade como motivo de afastamento. Seu art. 208 assevera: ela é de cinco dias. A lei 13.109/15, que elenca as medidas de proteção à maternidade para militares grávidas e adotantes, estabelece, em seu art. $6^{\circ}$, também o prazo de cinco dias. Situação similar ocorre na Lei $\mathrm{n}^{\circ}$ 12.514/11, que disciplina a profissão de médico-residente. Seu artigo $4^{\circ}$ disciplina tanto a licençapaternidade de cinco dias quanto à extensão da licença-maternidade em sessenta além dos conferidos constitucionalmente (art. $4^{\circ}, \S \S 2^{\circ}$ e $3^{\circ}$, respectivamente, da Lei $\mathrm{n}^{\circ} 12.514 / 11$ ).
} 
monoparentais masculinas. Nesse contexto, nota-se que o aparato legal contribui no mínimo para a manutenção e a reprodução de uma realidade bastante desigual no que diz respeito à divisão sexual do trabalho reprodutivo.

É o que se pode ver através do excessivo destaque à vinculação entre cuidado dos filhos e a maternidade. Isto é demonstrável não só através do tempo do direito à licença-maternidade frente ao seu similar masculino, como também pela extensão de toda uma gama de outros direitos somente às mulheres. Pode-se citar, à exemplo, o direito à creche em local de trabalho, além do direito à lactância. (ABRAMO; TODARO, 2005) O primeiro não considera que homens possam ter de levar seus filhos aos locais de trabalho pela ausência de pessoa disponível para cuidados e o segundo não propõe que os mesmos possam praticar cuidados mínimos e intransferíveis no transcurso de sua jornada de trabalho.

A disparidade legal entre os gêneros tem outros reflexos além da não responsabilização do homem no cuidado dos filhos decorrente da vinculação citada anteriormente. É, a partir desta que se criaram certos conceitos, como que a contratação feminina implica em custos maiores para os empregadores se comparados à contratação masculina, o que desemboca em menores salários para as mulheres $^{305}$. (ABRAMO; TODARO, 2005)

Tal diferença remuneratória, hoje, é diuturnamente associada a diferenças relativas aos maiores custos não-salariais a que incorreriam as empresas acaso contratassem mulheres. Uma vez arcando com a responsabilidade correspondente à reprodução, as mulheres seguem sendo responsáveis pelas funções básicas do universo doméstico e familiar. E isto, como afirmam as autoras supracitadas,

[...] afetaria seu comportamento em relação ao trabalho, provocando uma série de problemas, tais como uma taxa maior de absenteísmo, menor disponibilidade para fazer horas extras, para trabalhar em turnos noturnos, viajar ou capacitar-se, o que elevaria os custos (diretos e indiretos) associados a sua contratação. De acordo com essa linha de argumentação, estes custos mais elevados teriam sua origem na existência de normas de proteção contempladas pela legislação trabalhista, referente principalmente à maternidade e ao cuidado infantil (ABRAMO; TODARO, 2005, p. 21-22) [...] [e] que os menores salários das mulheres não se deveriam à existência de qualquer tipo de discriminação, mas sim estariam relacionados à necessidade que as empresas teriam de compensar esse custo supostamente maior de contratação, decorrente das normas especiais que protegem o seu trabalho (especialmente a maternidade) e dos "transtornos" causados pelas responsabilidades familiares. (ABRAMO; TODARO, 2005, p. 23)

Neste mesmo sentido, apontamos também que a

\footnotetext{
${ }^{305}$ Como demonstram Abramo e Todaro (2005, p. 22): "Segundo estudo recente da OIT, em 2000, as remunerações das mulheres eram, em média, $34 \%$ inferiores às dos homens por mês e $22 \%$ por hora trabalhada (dados relativos ao total de ocupados urbanos não-agrícolas de 15 países da América Latina, que correspondem a $92 \%$ do total da PEA não-agrícola da região) (OIT, 2001) ".
} 
[...] naturalização do papel das mulheres como responsáveis pela reprodução da família [...] se reflete, por exemplo, nas menores oportunidades de acesso das mulheres aos cargos de maior responsabilidade e hierarquicamente superiores, uma vez que elas, supostamente, teriam menos disponibilidade e até interesse em se dedicar ao trabalho dito produtivo. (GALIZA; FONTOURA; PINHEIRO, 2009, p. 855)

Todavia, não é se restringindo direitos sociais que se alcançam melhorias remuneratórias, incremento na qualidade de vida ou se consegue instituir condições mais justas de trabalho. São equivocadas as noções que consideram que o trabalho feminino é mais caro e apontam como causadores de tal carestia direitos sociais, impingindo-lhes a alcunha de custos não-salariais e prescrevendo cortes nestes mesmos direitos como forma de, supostamente, garantir maior liberdade na dinâmica empresarial, relegando à esfera do patronato a responsabilidade decisória pela concessão dos mesmos direitos perdidos, agora na condição de benefícios, a suas empregadas. (ABRAMO; TODARO, 2005)

Através dos estudos de Abramo e Todaro (2005) realizados na América Latina se comprovou que os custos monetários diretos para o empregador relativos aos direitos sociais ligados ao trabalho feminino são muito reduzidos, equivalendo à menos de $2 \%$ da remuneração bruta mensal recebida pelas mulheres.

Não se justifica, portanto, a correlação entre custos de proteção à maternidade e ao cuidado infantil com a permanência de toda uma gama de desigualdades que continuam a prejudicar mulheres no mercado de trabalho. (ABRAMO; TODARO, 2005)

Neste mesmo sentido, é da argumentação central do citado artigo que as diferenças na contratação de homens e mulheres são reforçadas não pela existência de legislação protetiva, mas sim pela forma através da qual as legislações trabalhista e previdenciária vigentes se apresentam. (ABRAMO; TODARO, 2005)

No tocante às licenças de trabalho para cuidado dos filhos no Brasil, é importante destacar que sua cobertura é limitada, se aplicando somente à trabalhadores registrados, empregados nas grandes empresas privadas e públicas. Claro, esta fatia dos trabalhadores compreende verdadeiramente a maior parcela da população brasileira, vez que o emprego formal cresceu na última década, passando os índices de trabalho informal e chegando em 2014 a cerca de 60\% dos trabalhadores do país (EXAME, 2014). Todavia, parcela considerável da população brasileira tem retornado ao emprego informal com o avanço da crise financeira e do desemprego (EXAME, 2016). Ou seja, por mais que se aumente o período de tempo da licença-maternidade para todas as trabalhadoras com vínculo de emprego formalizado, tal garantia tem potencial para beneficiar hoje 
pouco mais da metade de todas as famílias brasileiras e, num passado recente ${ }^{306}$, beneficiava menos da metade deste montante. (SORJ; FONTES; MACHADO, 2007)

Quando atentamos para o marco legal da Empresa Cidadã (Lei n $\left.{ }^{\circ} 11.770 / 08\right)$, percebemos que a disparidade é ainda mais elevada. Isto se dá mediante a escolha em se estender um direito social somente após a anuência do respectivo empregador (NEIVERTH; MANDALOZZO, 2009), tanto para o cadastro da empresa no programa como para o exercício deste mesmo, e limitando-o através de legislação infraconstitucional (CASTRO, 2008).

Estas reflexões anteriores são importantes para que entendamos, e trataremos disso mais a fundo adiante, que a opção pela licença-paternidade ser aumentada através da Lei nº 11.770/08 e não pela promulgação de lei específica a positivar as boas intenções do art. $7^{\circ}$, XIX, da Constituição Federal ou uma efetiva modificação deste artigo que estabeleça quantum referente a licençapaternidade, como é feito com a licença-maternidade no $7^{\circ}$, XVIII, da Constituição Federal pode ser preocupante.

Por fim, e é bom que se registre, ao analisarmos agora a legislação vigente e compararmos o rol de direitos alcançados pelas mulheres com os já estabelecidos visando a responsabilização dos homens no cuidado com o neonato ou com a criança recentemente inserida no núcleo familiar, percebemos gritante disparidade apresentada tanto para famílias monoparentais como para casais homoafetivos, (GALIZA; FONTOURA; PINHEIRO, 2009). E em ambas, é importante que se destaque, a pobreza ${ }^{307}$ a que estão expostas. (SORJ; FONTES; MACHADO, 2007). Neste mesmo sentido, Thomé (2009, pg. 42) destaca:

Mesmo com a Constituição de 1988, todavia, as desigualdades continuam. Conforme os dados apresentados na PNAD DE 2007, comparando os rendimentos por cor ou raça dentro dos grupos com igual nível de escolaridade, consegue-se perceber a persistência da discriminação de gênero, já que o rendimento médio real de todos os trabalhos da força de trabalho feminina correspondia a $66,1 \%$ da remuneração média masculina.

Após toda esta exposição, concordamos com as posições segundo as quais o entendimento social sobre a licença-paternidade no Brasil mudou, de certa forma, ainda que restrita. (GALIZA; FONTOURA; PINHEIRO, 2009). Hoje, se entende que ao homem devem ser dadas também a obrigação e o direito à participação ativa do cuidado dos filhos. (BARBA, 2016). Neste mesmo caminhar argumentativo, Galiza, Fontoura e Pinheiro (2009, p. 853) demonstram:

\footnotetext{
306 Passado este de meros nove anos. (SORJ; FONTES; MACHADO, 2007).

${ }^{307}$ Em conceituação de Sorj, Fontes e Machado $(2007,581)$, a“[ ...] pobreza foi definida como pessoas vivendo em famílias com renda per capita inferior à linha da pobreza. A linha da pobreza é o dobro da linha de indigência, que é definida pelos custos de uma cesta básica alimentar que contemple as necessidades de consumo calórico mínimo de um indivíduo. A linha da pobreza foi estimada, em setembro de 2005, em 163 reais. "
} 
Muitos comportamentos baseados nas convenções sociais de gênero também não se coadunam com as novas formas de organização da sociedade. Daí a importância de o Estado, por um lado, intervir para transformar esses comportamentos, reprodutores da desigualdade, e, por outro, incentivar aquelas transformações que vêm ocorrendo na sociedade.

Isto desemboca em parte do quadro que já temos: diferenças salariais e de condições de trabalho. (THOMÉ, 2009). É a insuficiência de políticas públicas que facilitem a gestão de demandas conflituosas entre trabalho e cuidados da família, aliada a baixa participação masculina na divisão do trabalho não remunerado que repercute nas oportunidades laborais das mulheres, notadamente das mães com filhos dependentes, que reforça as desigualdades de gênero no mercado de trabalho. (SORJ; FONTES; MACHADO, 2007)

Portanto, sem que se alcance certa conciliação entre a vida laboral e a familiar, as mulheres permanecerão tendo menos possibilidades de emprego, reduzido acesso à progressão justa de carreira, poucas condições de participação na mobilização sindical, deixando de usufruir de liberdade e lazer.

Segundo Sorj, Fontes e Machado (2007 apud GORNICK; MEYERS, 2003), são três os tipos de políticas públicas mais comuns em países desenvolvidos que buscam tal conciliação de trabalho e cuidados familiares. São elas: licenças do trabalho para cuidados dos filhos, sem perda de emprego e com manutenção salarial, além de outros benefícios monetários equivalentes; regulação do tempo de redução de jornada de trabalho para cuidados dos filhos sem custos econômicos para o desenvolvimento da carreira profissional; e o acesso à creches, pré-escolas e escolas em tempo integral como arranjo alternativo para pais em horário de trabalho. Todas estas políticas públicas são estendíveis a ambos os gêneros.

Deve-se, portanto, para assegurar o direito à proteção do mercado de trabalho da mulher, estabelecido no art. $7^{\circ}, \mathrm{XX}$, da Constituição Federal, implementar políticas públicas nesse sentido, que almejem corrigir diferenças nas condições e oportunidades de trabalho entre homens e mulheres. (GALIZA; FONTOURA; PINHEIRO, 2009)

Embora consideremos que não cabe aos poderes públicos a determinação da divisão de tarefas no ambiente doméstico ou imposição de escolha dos modos de convivência familiar, pensamos que é do Estado o dever de garantir às pessoas que possam ter, efetivamente, possibilidades para que vivam um modelo familiar igualitário. (THOMÉ, 2009)

E, aqui cabe citar Abramo (2008), ao ressaltarmos:

[...] é impossível reduzir significativamente o déficit de Trabalho Decente se não forem eliminadas as barreiras que impedem que grande parte da população dos países tenha acesso a oportunidades iguais de emprego devido ao seu sexo, à cor da sua pele, à sua idade, à sua origem nacional ou crença religiosa, à sua orientação sexual, ao fato de ser ou não uma pessoa com deficiência ou vivendo com HIV/AIDS. 
Concluímos, então, que, como ainda se correlaciona trabalho feminino com os ditos custos não-salariais oriundos de seus direitos sociais garantidos legal e constitucionalmente, entre eles a licença-maternidade, então, ao se estender estes mesmos direitos e responsabilidades relativos ao cuidado dos filhos aos homens, ao mesmo tempo que se valoriza o cuidado dos filhos e a convivência familiar, também tal transformação de valores incide sobre o trabalho feminino, que sofrerá cada vez menos do preconceito da onerosidade excessiva deste. Isto pode desembocar numa valorização salarial da remuneração feminina, marcadamente menor que a masculina.

Pode-se, além de reduzir as desigualdades de renda já ressaltadas anteriormente, repercutir num aumento no grau de oportunidades de emprego, além de se alcançar uma redução do preconceito na ascensão de carreira feminina e num maior acesso à convivência sindical, contribuindo assim para uma sociedade mais justa e igualitária.

Nos mesmos termos, Thomé afirma que

[...] a licença-paternidade ajuda a combater a discriminação estatística e, segundo Castillo (2007, p. 498/499), é o primeiro passo para uma igualdade real na repartição de papéis sociais, tendo como bens jurídicos protegidos a ajuda à recuperação biopsicológica da mãe, quando há parto, o cuidado do filho e o desenvolvimento da relação de convivência e de afeto entre pai (ou mãe em caso de casal homossexual) e filho. (THOMÉ, 2009, p. 49)

Embora no Brasil se apresente um quadro de desenvolvimento ainda precário de políticas públicas que visam repartir os custos dos cuidados de familiares, os altos índices de desrespeito à legislação e a pouca cobertura das políticas já existentes sejam um péssimo quadro da condição laboral no Brasil, (GALIZA; FONTOURA; PINHEIRO, 2009) se vislumbra hoje um legitimação social e política nascente para a mudança legislativa, ainda que pontual.

Presentemente, existem duas formas de abordagem em vias de garantir também ao homem o direito a licença para o cuidado dos filhos já alcançado pelas mulheres. Alguns países têm determinado que os homens tenham seu próprio tempo de licença, enquanto outros estabelecem que ambos os pais podem determinar como ocorrerá a divisão entre si de um tempo comum conferido por lei à ambos.

O viés adotado no Brasil é o de se conceder uma licença específica para cada pai, as quais apresentam diferenças quanto ao tempo concedido de acordo com o gênero do genitor ou adotante. A seguir analisaremos o Marco Legal da Primeira Infância, importante conquista legislativa a garantir o direito à licença-paternidade.

\section{A LEI N 13.257/16 - MARCO LEGAL DA PRIMEIRA INFÂNCIA.}


A norma que trataremos agora é exemplo de legislação compreensiva sobre a primeira infância. Ela terminou seu trâmite no Congresso Nacional e foi aprovada durante a feitura deste trabalho, todavia, não é só devido à coincidência temporal que a ela dedicamos especial atenção.

A Lei n ${ }^{0}$ 13.257/16 prevê, em seu art. 37, modificações no art. 473, da Consolidação das Leis do Trabalho - CLT. A ele são acrescidos os incisos X e XI: o primeiro dispondo sobre a possibilidade de dois dias resguardados ao trabalhador para o acompanhamento de consultas médicas e exames complementares durante a gravidez de sua esposa ou companheira; e o segundo reservando um dia ao ano para acompanhamento de filho de até seis anos em consulta médica.

No artigo seguinte, a Lei $n^{\circ} 13.257 / 16$ dispõe modificações nos arts. $1^{\circ}, 3^{\circ}, 4^{\circ}$ e $5^{\circ}$ da Lei $n^{\circ}$ 11.770/08, que cria o programa da Empresa Cidadã. As modificações na referida lei versam sobre um acréscimo de quinze dias de duração à licença-paternidade além dos cinco dias estabelecidos pelo art. 10 ADCT, bem como estabelece condições para tanto (art. $1^{\circ}$, II, da Lei $n^{\circ} 11.770 / 08$ )

Para usufruir dos quinze dias acrescidos pela Lei $n^{\circ} 13.257 / 16$, a empregada terá de solicitar a prorrogação até o final do primeiro mês após o parto e o empregado até dois dias úteis após o parto, bem como terá de comprovar participação em programa ou atividade de orientação sobre paternidade responsável (art. $1^{\circ}, \S 1^{\circ}$, I e II, da Lei n $\left.{ }^{\circ} 11.770 / 08\right)$. O direito é estendível aos pais adotantes ou em situação de guarda judicial (art. $1^{\circ}, \S 2^{\circ}$ da Lei n $\left.{ }^{\circ} 11.770 / 08\right)$.

A remuneração para ambos os pais é integral (art. $3^{\circ}$, da Lei $\left.n^{\circ} 11.770 / 08\right)$, todavia, é impedida a realização e qualquer atividade remunerada, sob pena, em caso de descumprimento, de perda do direito à licença estendida (art. $4^{\circ}$, caput c/c. art. $4^{\circ}$ parágrafo único, da Lei no 11.770/08).

Permanece inalterada a dedução tributária dos valores pagos como remuneração dos empregados (art. $5^{\circ}$, da Lei $\mathrm{n}^{\circ}$ 11.770/08). Como apontamos anteriormente em item referente à Lei de Empresa Cidadã, através da escolha por esse método de dedução tributária, restrito a empresas que declaram se faturamento pelo lucro real, se restringe a dimensão da licença-paternidade a uma quantidade pequena de empresas. (NEIVERTH; MANDALOZZO, 2009)

No art. 39 da Lei $\mathrm{n}^{\circ}$ 13.257/16 se esclarece que o Poder Executivo, nos conformes dos arts. 12 e 14 da Lei Complementar $n^{\circ}$ 101/00, estimará o montante de renúncia fiscal decorrente do disposto no art. 38, o qual altera o art. $5^{\circ}$, da Lei ${ }^{\circ}$ 11.770/08, apresentado anteriormente. Após, incluirá demonstrativo a acompanhar o projeto de lei orçamentária cuja apresentação deve se dar após sessenta dias da publicação da Lei n ${ }^{\circ} 13.257 / 16$.

Os artigos 38 e 39 da Lei no 13.257/16 só produzirão seus efeitos a partir do primeiro dia do exercício subsequente àquele em que for implementado do disposto no art. 39 (art. 40 da Lei ${ }^{\circ}$ 13.257/16). 


\section{CONSIDERAÇÕES FINAIS}

Esperamos que, ao longo desta exposição, possamos ter esclarecido o leitor de que o preconceito de gênero existe e se apresenta também com o uso da lei.

Acreditamos ter conseguido demonstrar que é positivo conferir direitos relativos à maternidade à mulher, mas que a forma pela qual se deu o alcance destes também gerou consequências econômicas para o trabalho e renda destas.

Vivemos numa realidade na qual o mesmo machismo que permanece tratando mulheres como "gênero frágill", também reverbera em suas relações de trabalho. É esse o tipo de pensamento que barra progressões de carreira ao pensar na não dedicação profissional das mulheres. É esta a linha de raciocínio que atribui menores remunerações para a mesma atividade e precariza as condições de trabalho feminino, afinal, concluem, contratar mulheres é um custo adicional extenuante, pois contém em si toda uma gama de dividendos negativos relativos à gestação e aos primeiros cuidados dos nascituros.

Uma vez apresentada a legislação nacional atual, buscamos comprovar que é equivocada a premissa que o trabalho feminino é mais caro que o masculino. Apontamos, através de pesquisas e estudos comparados tratando da legislação protetiva da maternidade na América Latina, que somente os custos relativos a creches é que são diretamente vinculados ao trabalho feminino. Portanto, nem o auxílio-maternidade nem a licença-maternidade são custos diretamente atrelados ao trabalho feminino. E mesmo aqueles que o são, não constituem mais que dois por cento do faturamento das empresas estudadas.

Ainda assim, é recomendável que se altere a legislação também sobre esse tema, de modo a desatrelar o trabalho feminino à necessidade de creches. A lei, neste caso, também reflete o machismo da sociedade, ao qual nos referimos anteriormente. Esquece-se que homens também tem filhos, que podem cria-los sozinhos, que nem toda família é formada com a presença de uma mãe, e que as crianças filhas destas também precisam de creches.

A norma, ao vincular somente ao trabalho feminino a necessidade de ambientes para os cuidados e primeira educação de crianças ao invés de simplesmente se omitir, não identificando o gênero do genitor responsável, acaba por gerar rejeição à contratação feminina.

Quando nos deparamos com tal entendimento dominante e infundado acerca da carestia do trabalho feminino, o questionamento passa a ser como fazer para alcançar uma igualdade real. Eis o paradigma, a indagação originária, que serve de fonte para o presente artigo. 
Buscamos, através deste trabalho, reverberar a ideia de que a licença-paternidade é o primeiro passo para se alcançar tal igualdade na repartição do papel social do cuidado dos filhos e o desenvolvimento da relação de convivência e de afeto, em qualquer das diversas formas de família.

Acreditamos também que pela aprovação da licença-paternidade perpassa a melhoria das condições de trabalho da mulher, bem como a proteção ao trabalho feminino. Ao se conferir direitos iguais e se valorizar o cuidado dos filhos, corrigindo defasagens legais não alinhadas com parte dos ideais presentes na Constituição Federal, também se contribui para a equiparação salarial e de condições de trabalho de ambos os gêneros.

Em tópico próprio, quando abordamos a situação da lei que instituiu o Programa da Empresa Cidadã antes da aprovação da Lei $n^{\circ} 13.257 / 16$, argumentamos que não é a melhor maneira de se conferir direitos trabalhistas a mediante anuência patronal, conforme a Lei $\mathrm{n}^{\circ}$ 11.770/08. Além disso, a mesma lei peca por sua pouca penetração social ao restringir o critério de sua desoneração a empresas que declaram seu lucro através da modalidade do Lucro Real, de pouca abrangência.

Apresentam-se assim duas categorias de trabalhadores: aqueles que tem o privilégio de trabalhar numa empresa que faz parte do Programa da Empresa Cidadã e aqueles que não. Dentre os primeiros, ainda assim, só poderão usufruir do direito à licença-paternidade aqueles trabalhadores específicos que tiverem o privilégio de obter a anuência patronal, mesma situação na qual já se enquadram as trabalhadoras de tais empresas. Deve-se, sim, conferir direitos a todos os trabalhadores, e não permitir se enxergue como um privilégio de poucos o alcance de um direito.

Contudo, entendemos que é positiva a promulgação da Lei $n^{0}$ 13.257/16. Aos trabalhadores, ainda que a poucos, é agora possibilitada a possibilidade de uma presença mais duradoura quando do nascimento ou adoção de seus filhos. Laços melhores serão construídos após um cuidado maior presente.

Além disto, talvez uma diferença entre aqueles que são beneficiados pelo direito à uma licença-paternidade mais longa traga maiores reinvindicações neste sentido, talvez resultando numa legislação progressiva acerca da duração da licença-paternidade nos moldes dos países que estudamos neste artigo. Tal mudança normativa poderá vir a ser alcançada tanto por dispositivo programático presente no texto dela ou por uma revisão periódica do texto legal.

Por fim, esperamos que a Lei $n^{\circ} 13.257 / 16$, ao conter em si disposição acerca da licençapaternidade, ajude a reduzir parte das desigualdades de gênero presentes no mundo de trabalho ao estimular o compartilhamento entre os pais das responsabilidades pelo cuidado de seus filhos.

Acreditamos que a existência da licença-paternidade é parte do caminho para uma existência humana mais sadia, igualitária e livre. Ela contribui efetivamente para a melhora da remuneração e das condições de trabalho das mulheres, além de ter uma relevância simbólica ainda maior, ao não 
limitar o dever de conciliação entre a vida profissional e as responsabilidades familiares somente como uma preocupação destas.

\section{REFERÊNCIAS}

ABRAMO, L. Mulher no mercado de trabalho: participação feminina cresce, mas desigualdade persiste. Disponível em: <http://www.anamatra.org.br/noticias/mulher-no-mercado-de-trabalhoparticipac-o-feminina-cresce-mas-desigualdade-persiste09296199725285359 >. Acesso em 23 de fev. 2016.

ABRAMO, L; TODARO, R. Custos de trabalho e reprodução social em cinco países latinoamericanos. In: ABRAMO, L. (ed.). Questionando um mito: custos do trabalho de homens e mulheres. Brasília: Organização Internacional do Trabalho, 2005. p.17-64

. "Custos do trabalho de homens e mulheres na América Latina". In: COSTA, Albertina et al. (Orgs.). Mercado de trabalho e gênero: comparações internacionais. Rio de Janeiro: FGV, 2008. p. 141-158.

BRASIL. Pesquisa Nacional de Amostra de Domicílios (PNAD). Rio de Janeiro: IBGE, 2008.

Constituição (1988). Constituição da República Federativa do Brasil: promulgada em 05 de outubro de 1988. Brasília, DF: Senado, 1988.

Decreto-lei ${ }^{\circ} 5.452$, de $1^{\circ}$ de maio de 1943. Aprova a Consolidação das Leis do Trabalho. Disponível em: < http://www.planalto.gov.br/ccivil_03/decreto-lei/Del5452.htm >. Acesso em 18 de abr. 2016.

Decreto-lei $n^{\circ} 229$, de 28 de fevereiro de 1967. Altera dispositivos da Consolidação das Leis do Trabalho, aprovada pelo Decreto-lei $\mathrm{n}^{\circ} 5.452$, de $1^{\circ}$ de maio de 1943, e dá outras providencias. Disponível em: < http://www.planalto.gov.br/ccivil_03/decreto-lei/Del0229.htm >. Acesso em 18 de abr. 2016.

Lei $\mathrm{n}^{\circ}$ 8.112, de 11 de dezembro de 1990. Dispõe sobre o regime jurídico dos servidores públicos civis da União, das autarquias e das fundações públicas federais. Disponível em: < http://www.planalto.gov.br/ccivil_03/leis/L8112cons.htm >. Acesso em 18 de abr. 2016.

Lei $\mathrm{n}^{\mathrm{o}}$ 10.710, de 05 de agosto de 2003. Altera a Lei no 8.213, de 24 de julho de 1991, para restabelecer o pagamento, pela empresa, do salário-maternidade devido à segurada empregada gestante. Disponível em: < http://www.planalto.gov.br/ccivil_03/leis/2003 /L10.710.htm >. Acesso em 10 de abr. 2016. 
Lei n ${ }^{\circ} 11.770$, de 9 de setembro de 2008. Cria o Programa Empresa Cidadã, destinado à prorrogação da licença-maternidade mediante concessão de incentivo fiscal, e altera a Lei no 8.212, de 24 de julho de 1991. Disponível em: <http://www.planalto.gov.br /ccivil_03/_ato2007-2010/2008/lei/111770.htm>. Acesso em: 10 mar. 2016.

Lei $n^{\circ} 12.514$, de 28 de outubro de 2011. Dá nova redação ao art. 4o da Lei no 6.932, de 7 de julho de 1981, que dispõe sobre as atividades do médico-residente; e trata das contribuições devidas aos conselhos profissionais em geral. Disponível em: < http://www.planalto.gov.br/ccivil_03/_ato2011-2014/2011/lei/112514.htm>. Acesso em 18 de abr. 2016.

Lei $\mathrm{n}^{\circ} 13.109$, de 25 de março de 2015. Dispõe sobre a licença à gestante e à adotante, as medidas de proteção à maternidade para militares grávidas e a licença-paternidade, no âmbito das Forças Armadas. Disponível em: < http://www.planalto.gov.br/ccivil_03/_Ato20152018/2015/Lei/L13109.htm >. Acesso em 18 de abr. 2016.

Lei $\mathrm{n}^{\circ} 13.257$, de 08 de março de 2016. Dispõe sobre as políticas públicas para a primeira infância e altera a Lei no 8.069, de 13 de julho de 1990 (Estatuto da Criança e do Adolescente), o Decreto-Lei no 3.689, de 3 de outubro de 1941 (Código de Processo Penal), a Consolidação das Leis do Trabalho (CLT), aprovada pelo Decreto-Lei no 5.452, de 1o de maio de 1943, a Lei no 11.770, de 9 de setembro de 2008, e a Lei no 12.662, de 5 de junho de 2012. Disponível em: < http://www.planalto.gov.br/ccivil_03/_Ato2015-2018/2016/Lei/L13257

.htm>. Acesso em 18 de abr. 2016.

BOSCHETTI, I. Seguridade social no Brasil: conquistas e limites à sua efetivação. Programa de Capacitação em serviço social: direitos sociais e competências profissionais. Brasília, UnB/CEFSS, 2009.

CASTRO, F. Ampliação da licença-maternidade beneficia empresas. Disponível em: <http://www.pstu.org.br/node/13737 >. Acesso em: 14 de fev. 2016.

EXAME. Disponível em: <http://exame.abril.com.br/economia/noticias/emprego-informal-nobrasil-cai-de-55-para-40-em-dez-anos>. Acesso em 18 de abr. 2016.

Disponível em: <http://exame.abril.com.br/economia/noticias/trabalho-informal-e-maioriaem-59-4-das-cidades-brasileiras>. Acesso em 18 de abr. 2016.

GALIZA, M.; FONTOURA, N.; PINHEIRO, L. Novos arranjos familiares, velhas convenções sociais de gênero: a licença-parental como política pública para lidar com essas tensões. Revista Estudos Feministas, Florianópolis, nº17 (3), 851-859, setembro/dezembro de 2009. 
BARBA, M. D. Licença-paternidade de 20 dias: o que dizem os pais e qual será o impacto econômico.Disponível em:< http://www.bbc.com/portuguese/noticias/2016/02/160205_ licenca_paternidade_ampliada_mdb>. Acesso em 07 de fev. 2016.

MENDES, G. F. Curso de direito constitucional / Gilmar Ferreira Mendes, Paulo Gustavo Gonet Branco. - 9. Ed. rev. e atual. - São Paulo: Saraiva, 2014.

MILÍCIO, G. Disponível em: <http://www.conjur.com.br/2007-out-18/licenca maternidade_maior_ajuda_atrapalhar>. Acesso em 12 de fev. 2016.

NEIVERTH, E.; M. H. B., MANDALOZZO, S. S. N. A Licença-maternidade e sua ampliação facultativa. Revista do Tribunal Regional do Trabalho da $9^{a}$ Região, Curitiba, a. 34, n. 63, julho/dezembro de 2009.

ORGANIZAÇÃO INTERNACIONAL DO TRABALHO. Convenção sobre o amparo à maternidade, $\mathrm{n}^{\circ}$ 183, 16 de jun. 2000. Adota medidas de amparo à maternidade na legislação internacional. Disponível em: <http://direitoshumanos.gddc.pt/3_4/IIIPAG3_4_4_A.htm> Acesso em: 11 de mar. 2016.

Convenção sobre a proteçãoda maternidade, $\mathrm{n}^{\circ}$ 103, 29 de jun. 1952. Adota medidas de amparo à maternidade na legislação internacional. Disponível em: 〈http://www.oit.org.br/node/524> Acesso em: 23 de fev. 2016.

Panorama laboral de América Latina. n. 8. Lima: OIT, 2001.

RECEITA FEDERAL DO BRASIL, MINISTÉRIO DA FAZENDA. Lucro Real. Disponível em: <http://www.receita.fazenda.gov.br/pessoajuridica/dipj/2000/orientacoes/lucroreal .htm\#Conceito>. Acesso em 15 de fev. 2016.

SILVA, A. M. O direito do trabalho da mulher e a maternidade. In: Âmbito Jurídico, Rio Grande, X, n. $40, \quad$ abr 2007. Disponível em: < http://www.ambitojuridico.com.br/site/index.php?n_link=revista_artigos_leitura\&artigo_id=1751 >. Acesso em 05 de abr. 2016.

SORJ, B; FONTES, A; MACHADO, D. C. Políticas e Práticas de Conciliação entre Família e Trabalho no Brasil. Revista Cadernos de Pesquisa, São Paulo, v. 37, n. 132, p. 573-594, julho/dezembro de 2007. 


\title{
PATERNITY LEAVE AU BRASILIENNE: A CRITICAL ANALYSIS OF THE FIRST CHILDHOOD LEGAL MARK
}

\begin{abstract}
The present article seeks to demonstrate the importance of paternity leave for valorization of feminine work and to changing the understanding about fatherhood, improving the relations between fathers and sons. We start our argument through the exposition of current legislation in Brazil, weaving commentaries on Lei $n^{\circ} 11.770 / 08$, which establishes the Citizen Enterprise Program. Afterwards, we seek to demonstrate, starting from several studies, the intimate connections between the right to paternity leave and the valorization of the feminine work. At end, we present the legislative proposals processing in the National Congress and analyze the text of Lei $n^{\circ} 13.257 / 16$, which institutes the Legal Mark for First Childhood. We conclude for the necessity of a legal polity for paternity leave that is independent and dissociated between parents.
\end{abstract}

Keywords: Paternity Leave; Social Right; Feminine Work; Legislative proposals. 